\title{
The deviating eyes of Michelangelo's David
}

\author{
Saad Shaikh $\mathrm{MD}^{1} \quad$ James Leonard-Amodeo ${ }^{2}$
}

J R Soc Med 2005;98:75-76

'In every block of marble I see a statue as plain as though it stood before me, shaped and perfect in attitude and action. I have only to hew away the rough walls that imprison the lovely apparition to reveal it to the other eyes as mine see it.'-Michelangelo

In 1501 Michelangelo received a commission from the Guild of Wool Merchants of Florence to carve out a giant statue for one of the buttresses of the Cathedral of Florence. The David was started in 1501 when Michelangelo was only 26 years of age, and finished in 1504, when he was not yet 30 , and stands as a testament to Michelangelo's mastery of the human form and sculpture. Previous works had shown the subject just after he had slain and beheaded Goliath. Michelangelo's David broke new ground by depicting a 'most beautiful animal preparing to kill—not by savagery and brute force, but by intellect and skill'. ${ }^{1}$

Direct anatomical dissection was forbidden during the Renaissance and artists who wished to view the inside of the human body had to do so almost in secret. When Michelangelo fashioned a life-sized wooden crucifix altarpiece for the Santo Spirito in Florence, the prior allowed him access to bodies awaiting burial. ${ }^{2}$ The practice of anatomy became a passion for Michelangelo and his works correctly demonstrated numerous anatomical structures. He even contemplated publishing a treatise on anatomy together with his physician, Realdo Colombo, who treated him for kidney stones and later rose to become professor and medical consultant to the Vatican. ${ }^{3}$ So real were Michelangelo's works that they were used as models by other artists of the era and for centuries afterwards. In addition, 'pathological' features in his paintings and sculptures have attracted much attention in medical journals. $^{4}$

For all Michelangelo's mastery of human anatomy, the David possesses certain anatomical imperfections. The right hand is bigger than the left with an enlarged abductor digiti minimi - suggested as a device to draw attention to the stone as a symbol of his courage and physical power. ${ }^{5}$ Yet the most significant anomaly is in the David's eyes, which seem to manifest an exodeviation. The right eye is in the

${ }^{1}$ Central Florida Retina Consultants, 44 Lake Beauty Drive Suite 300, Orlando, Florida 32806, USA

${ }^{2}$ Online Fine Arts Magazine (http://www.sierra-arts.net)

${ }^{*}$ Correspondence to: Saad Shaikh MD primary position while the left eye appears to be looking out to the left (Figure 1). The likely reason why this detail has been unrecognized for hundreds of years is that most viewers have been physically unable to examine the David at eye level and at arms-length. The statue, about 5 metres tall in addition to its supporting pedestal, was meant to be viewed from below and, presumably, at a distance. In 1999, the Digital Michelangelo Project, led by Stanford University and Marc Levoy, professor of computer science and engineering, rendered a three-dimensional computer model that permitted the work to be viewed from different angles and with varying light intensity and colour modulation. ${ }^{6}$ A digitally rendered direct frontal image-a perspective not easily attainable by photography and

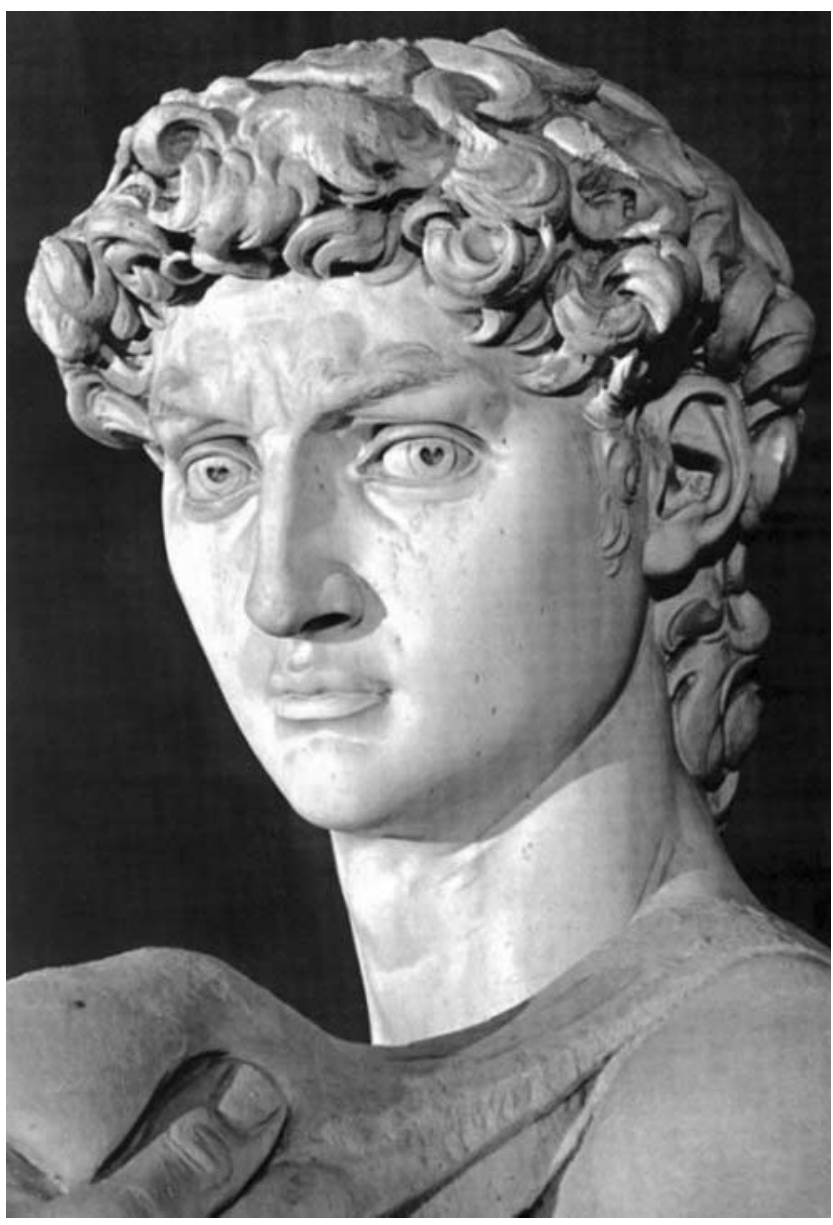

Figure 1. Head of David. On eye level and rotated slightly left (from the statue's perspective) of the frontal plane, the left eye fixates on the viewer while the right eye appears to be looking at the distance away from the viewer. [Courtesy of The Fine Arts Magazine] 


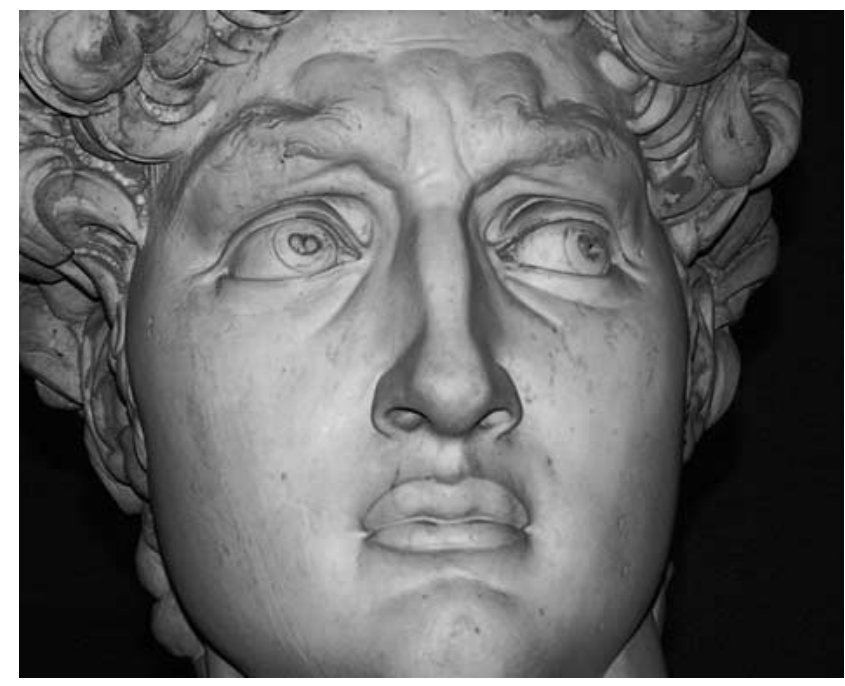

Figure 2. Head of David. Computer rendered frontal image of the David confirming an exodeviation. [Courtesy of the Digital Michelangelo Project and Stanford University]

certainly not by floor observation-indicated that the David is exotropic (Figure 2).

When one views the David closely, a general asymmetry of proportion is evident, with the head and upper body proportionally larger than the lower body. Lois FichnerRathus in her classic textbook Understanding Art notes that a new concept of artistic space takes form with the David's positioning:

No longer does the figure remain still in a Classical contraposto stance, but rather extends into the surrounding space away from a vertical axis. This movement outward from a central core forces the viewer to take into account both the form and the space between and surrounding the forms - in order to appreciate the complete composition. ${ }^{1}$

To comprehend the sculpture fully a viewer must circumambulate the work, and then finds the David's appearance changing dramatically. The right-hand side of the statue is smooth and composed while the left-side, from the outstretched foot all the way up to the dishevelled hair, is openly active and dynamic. To achieve this effect, Michelangelo deliberately made body parts disproportionate.

As regards the eyes, only one can be seen at a time as the observer walks around the statue. Michelangelo uses the David's exodeviation as an artistic tool. Approaching the statue from its left, the viewer notes that the left eye is staring towards (and above) him, as if focusing cunningly on the giant Goliath. However, the right eye is not fully visible from this angle because it is hidden behind the sling. If one stands to the statue's right and circles around the right, the right eye remains visible but the left eye disappears. Michelangelo must have calculated every angle and considered the position of the viewer when carving out the eyes. The left eye accords with the direction of the body's intended move-David would be throwing the stone toward his left and the eye, naturally, would fixate its gaze in that direction. The right eye, when combined with the rest of the body seen from the right side, accords perfectly with those qualities the commissioners of the work wanted the statue to reflect-power, cunning and intelligence.

Albeit we all interpret art according to individual experience and no doubt the biases of a physician are affected by the study of medicine, most would agree that Michelangelo fashioned his David with a sublime balance of power, intellect, and neoclassical beauty. An ophthalmologist, though, would find it difficult to believe that an exotropic David could have successfully disposed of Goliath with a sling.

\section{REFERENCES}

1 Fichner-Rathus L. Understanding Art. Englewood Cliffs, New Jersey: Prentice Hall, 1995

2 Symonds JA. The Life of Michelangelo Buonarroti. Project Gutenberg EBook. Available at [www.gutenberg.net/1/1/2/4/11242/11242.txt] accessed 25 April 2004

3 Eknoyan G, De Santo NG. Realdo Colombo (1516-1559). A reappraisal. Am J Nephrol 1997;17:261-8

4 Strauss RM, Marzo-Ortega H. Michelangelo and medicine. J R Soc Med 2002;95:514-15

5 King R. Michelangelo and the Pope's Ceiling. New York: Penguin USA, 2003

6 Levoy M. The Digital Michelangelo Project. Available at [http:// graphics.stanford.edu/projects/mich/] accessed 25 April 2004 